\title{
NEST ARCHITECTURE AND BROOD DEVELOPMENT TIMES IN THE PAPER WASP, POLISTES EXCLAMANS (HYMENOPTERA: VESPIDAE) *
}

\author{
By J. E. Strassmann and M. C. Ferreira Orgren \\ Biology Department, \\ Rice University, \\ Houston TX 77251
}

\begin{abstract}
One of the distinctive features of social insects is that they rear their brood in nests. In the Vespidae these nests are typically constructed of paper; they have one or several layers of cells, and may have an outer envelope of paper (Jeanne 1975). Nest architecture has been interpreted as a means of minimizing vulnerability to nest predators, particularly ants (Jeanne, 1975; 1979). Another factor that may contribute to nest design is a limitation on efficient food distribution to larvae when there are many cells in a single layer. For example if foragers tend to land on one part of the nest and then begin feeding the nearest larvae, unequal food distribution would result. The purpose of this study was to examine the influence of cell location on brood development times of Polistes exclamans Viereck. Also examined were the roles of time of year, numbers of workers, and larvae per worker as factors influencing development times. P. exclamans was chosen as a study organism because all cells are in one layer, without an envelope; nests are approximately circular, and have a single off-center pedicel usually located towards the top of the nest. Cells near the pedicel are the oldest. These features make nests of $P$. exclamans among the more simple types of nests. In central Texas nests of $P$. exclamans vary greatly in size, reaching an upper limit of about 500 cells (Strassmann, personal observation).
\end{abstract}

\section{MethodS}

Three nests representing small, average and large nests were chosen for observation at Brackenridge Field Laboratory of the University of Texas at Austin, Texas. These nests appeared to be

*Manuscript received by the editor May 15, 1983. 
generally representative of their size classes. In 1978 nest 83 (44 cells) and nest 22 (220 cells) and in 1979 nest 27 (345 cells) were observed (Fig. 1). Contents of cells were scored every other day on a cell map, and numbers of females associated with the nest were marked and counted. Nest 22 was observed from 12 June to 14 August; nest 83 was observed from 19 June to 14 August; and nest 27 was observed from 6 June to 18 August. From mid June to mid August mean daily termperatures changed very little. Average monthly temperatures were $23.5^{\circ} \mathrm{C}$ for June, $24.7^{\circ} \mathrm{C}$ for July and $24.8^{\circ} \mathrm{C}$ for August (30 year averages for Austin, Texas, National Weather Service). When an adult emerged from a cell an egg was laid in it so all cells contained brood. In the rest of this paper the nests will be referred to as the small (nest 83) medium (nest 22) and large (nest 27) nest.

For the purposes of analysis the medium and large nests were divided into 4 regions, and the small nest was divided into 3 regions (Fig. 1). The regions were chosen by first mapping development times of brood in every cell on a cell map, and then choosing regions that were homogeneous within themselves and as different as possible from other regions. This technique maximized the probability that differences among regions would be found. On all nests region 1 is the oldest, directly in front of the nest pedicel. Region 2 is the center of the nest. Regions 3 and 4 are edge regions. The medium nest may appear in the figure to have two lobes to it but they were actually contiguous. The cells were deformed somewhat due to contact with 1 inch chicken wire mesh which ran down the center of the nest.

Large sample sizes, normal distribution of data and nearly equal variances allowed us to use parametric statistics in this study. Because of its size the small nest was omitted from some of the analyses. All statistical analyses were performed using Statistical Analysis System (SAS) or Statistical Package for the Social Sciences (SPSS).

\section{RESULTS}

Average development times of eggs varied from 9 to 14 days depending on the nest (Table 1). Eggs took significantly longer to develop on the small nest (small compared to medium nest $t=5.45$, 

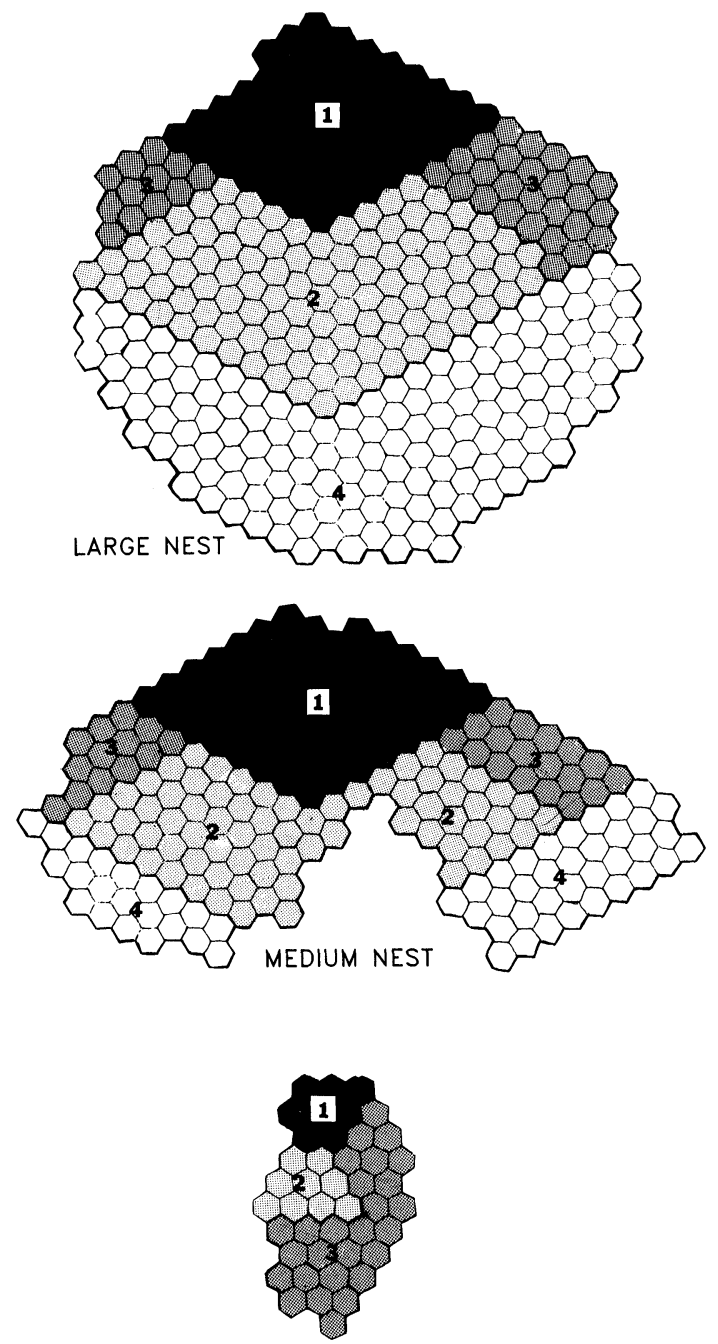

SMALL NEST

Figure 1. Cell maps of nests in the study indicating nest regions. 
$\mathrm{df}=381, \mathrm{p}<0.001 ;$ small compared to large nest, $\mathrm{t}=8.55, \mathrm{df}=542$, $\mathrm{p}<0.001)$. There were no differences in egg development times between the medium and large nests $(\mathrm{t}=0.57, \mathrm{df}=839$, n.s.). Average larva development times varied from 13 to 18 days depending on nest (Table 1). The small nest and the large nest did not differ in average larva development times $(t=0.68, d f=343$ n.s. $)$. However they both had longer larva development times than did the medium nest (small compared to medium, $\mathrm{t}=4.84, \mathrm{df}=322, \mathrm{p}<0.001$; medium compared to large, $\mathrm{t}=8.89, \mathrm{df}=611, \mathrm{p}<0.001$ ). Pupa development times averaged 13 days on all nests, and there were no significant differences among the nests.

Development times of eggs, larvae and pupae did not vary significantly from one region of the nest to another on the small and medium nests (Tables 2-4, Fig. 2). In the large nest both eggs and larvae developed most quickly in region 1 (the oldest part of the nest), and most slowly in the edge regions 3 and 4 (Tables 2-4, Fig. 2). In no case did region of nest explain more than $10 \%$ of the variance in development time.

Date did not have a consistent effect on development times. Eggs developed more slowly towards the end of the season in the large nest, and more quickly towards the end of the season in the small nest (Table 5). There was no change in egg development time with date in the medium nest. Larva development time increased with date in both the large and the medium nest, and decreased with date in the small nest (Table 5). Development times of pupae did not change with date in the large nest, but decreased with date in the medium and small nests (Table 5). Date explained 35\% to 51\% of the variance in larva development times depending on nest. It explained smaller percentages of the variance in egg and pupa development times except on the small nest (Tables 2-4).

Interaction between date and region of nest was examined using a 2-way ANOVA (Tables 2-4). There was a significant $(p<0.05)$ interaction between date and region of nest for egg and larva development times in the large nest that explained $7 \%$ and $5 \%$ of the variance respectively (Tables $2-4$ ). This interaction thus explains a trivial amount of the variance in development compared to that explained by date.

The effect of numbers of females tending the nest was found to be quite variable. Looking only at the medium and large nests, it 
TABLE 1. Average brood development times per nest.

\begin{tabular}{rrrr}
\hline & X & S.D. & N \\
\hline Egg development time & & & \\
Small nest & 13.81 & 5.67 & 43 \\
Medium nest & 9.58 & 4.67 & 340 \\
Large nest & 9.43 & 2.92 & 501 \\
& & & \\
Larva development time & & & \\
Small nest & 18.18 & 3.71 & 28 \\
Medium nest & 13.39 & 5.09 & 296 \\
Large nest & 17.39 & 6.03 & 317 \\
& & & \\
Pupa development time & & & \\
Small nest & 12.74 & 2.18 & 19 \\
Medium nest & 13.05 & 4.31 & 218 \\
Large nest & 13.00 & 3.83 & 268 \\
\hline
\end{tabular}

TABLE 2. ANOVA of the effects of date and location in nest on egg development times.

\begin{tabular}{rccc}
\hline & \multicolumn{2}{c}{ Main Effects } & $\begin{array}{c}\text { Interaction } \\
\text { Location in nest } \\
\times \text { date }\end{array}$ \\
\hline $\begin{array}{r}\text { Small nest } \\
\text { Lum of squares }\end{array}$ & 68 & 648 & 76 \\
$\mathrm{~F}$ & 2.1 & $1.31^{* * *}$ & 1.5 \\
df & 2 & 3 & 3 \\
\% of variance explained & 5 & 48 & 6 \\
Medium nest & & & \\
Sum of squares & 56 & 1184 & 319 \\
$\mathrm{~F}$ & 1.0 & $16.3^{* * *}$ & 1.5 \\
df & 3 & 4 & 12 \\
\% of variance explained & 1 & 16 & 4 \\
Large nest & & & \\
Sum of squares & 105 & 100 & 278 \\
$\mathrm{~F}$ & $4.5^{* *}$ & $3.2^{* *}$ & $3.2^{* * *}$ \\
$\mathrm{df}$ & 3 & 4 & 11 \\
$\%$ of variance explained & 3 & 2 & 7 \\
\hline
\end{tabular}

$\mathrm{df}=$ degrees of freedom, ${ }^{*} \mathrm{p}<0.05,{ }^{* *} \mathrm{p}<0.01,{ }^{* * *} \mathrm{p}<0.001$ 
was found that egg development time increased with number of females on the large nest and decreased on the medium nest (Table 5). Larva development times increased with numbers of females on both large and medium nests. Pupa development time decreased with increasing numbers of females on the large nest, and did not change significantly on the medium nest (Table 5).

Partial correlations of development time with date were calculated controlling for numbers of females, since numbers of females increased with date. Development times of larvae increased significantly $(\mathrm{p}<0.01)$ with date on the large and medium nests when numbers of females were controlled for (Table 5). Development times of eggs decreased with increasing numbers of females on the medium nest when date was controlled for. Development times of larvae and pupae decreased with increasing numbers of females on the large nest when date was controlled for.

The ratio of larvae to females on the large nest was $3.11 \pm$ S.D.2.05, and on the medium nest it was $1.23 \pm$ S.D.0.47. Development time of larvae was slower when there were more larvae per female on the large nest $(r=-0.13, p<0.03, N=317)$. The correlation was in the same direction on the medium nest, but was not significant $(\mathrm{r}=-0.10, \mathrm{p}>0.1, \mathrm{~N}=296)$ perhaps because there averaged more females per larva.

\section{Discussion}

The results presented here do not offer strong support for the hypothesis that location of brood affects development rates. Centrally located brood developed no more quickly than did edge brood. Feeding efficiency does not appear to be limiting the size of nests. Foragers arriving on the nest with prey typically share it with 3 or 4 other females who each visit many larvae (Strassmann, unpub.). The result seems to be even distribution of food. Though the largest nest did show a significant region effect for egg and larva development, it explained less than $7 \%$ of the variance. Perhaps an even larger nest would show a more marked effect. West Eberhard (p. 38, 1969) suggested that 7 pupae in the center of a nest she observed and 8 pupae towards the edge of the nest had long and short pupal periods respectively because of differences in larva nutrition. She suggested that better-fed larvae in the center of the nest would have longer pupa development periods. This study does 


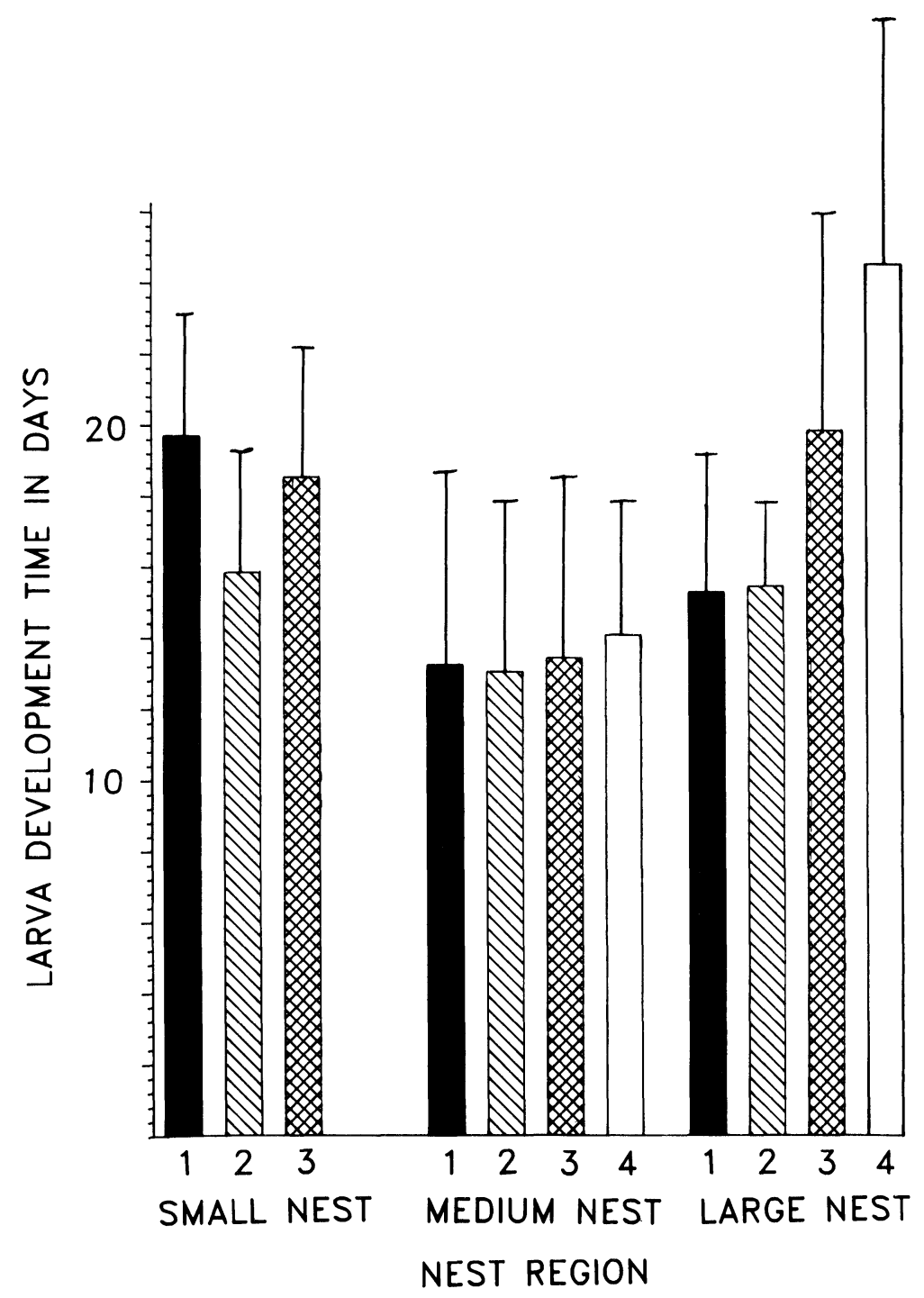

Figure 2. Development times of larvae in different regions of each nest. Bars indicate means and lines indicate standard deviations. 
TABLE 3. ANOVA of the effects of date and location in nest on larva development times.

\begin{tabular}{|c|c|c|c|}
\hline & \multicolumn{2}{|c|}{ Main Effects } & \multirow{2}{*}{$\begin{array}{c}\text { Interaction } \\
\text { Location in nest } \\
\times \text { date } \\
\end{array}$} \\
\hline & Location in nest & Date & \\
\hline \multicolumn{4}{|l|}{ Small nest } \\
\hline Sum of squares & 25 & 148 & 22 \\
\hline$F$ & 1.4 & 5.6 & 1.3 \\
\hline df & 2 & 3 & 2 \\
\hline$\%$ of variance explained & 7 & 40 & 6 \\
\hline \multicolumn{4}{|l|}{ Medium nest } \\
\hline Sum of squares & 35 & 2631 & 49 \\
\hline$F$ & 0.7 & $37.0^{* * *}$ & 0.3 \\
\hline df & 3 & 4 & 11 \\
\hline$\%$ of variance explained & 1 & 35 & 1 \\
\hline \multicolumn{4}{|l|}{ Large nest } \\
\hline Sum of squares & 821 & 5842 & 568 \\
\hline$F$ & $19.4 * * *$ & $138.1 * * *$ & $5.0^{* * *}$ \\
\hline df & 3 & 3 & 8 \\
\hline$\%$ of variance explained & 7 & 51 & 5 \\
\hline
\end{tabular}

$\mathrm{df}=$ degrees of freedom, ${ }^{*} \mathrm{p}<0.05,{ }^{* *} \mathrm{p}<0.01,{ }^{* * *} \mathrm{p}<0.001$

not support her conclusions.

High mean daily temperatures characterized the entire period of this study, essentially eliminating temperature as a variable. The slight increase in temperature over the season would be expected to speed up development if it had any effect at all. The increase in development time with date may best be explained by a gradual seasonal decrease in abundance of prey. Later in the season larvae may take in less nutrition per day, which results in longer times spent as larvae. Also there is usually a gradual increase in size of adults over the season in P. exclamans (Strassmann, unpub.). Larvae destined to become larger adults may require longer feeding periods. In P. metricus midsummer workers are as large as queens (Haggard and Gamboa, 1980). These large workers were larvae when worker to larva ratios were at their maximum (Haggard and Gamboa, 1980).

Development times of larvae were shortest on the medium nest which had the fewest larvae per worker. There are probably advan- 
TABLE 4. ANOVA of the effects of date and location in nest on pupa development.

\begin{tabular}{|c|c|c|c|}
\hline & \multicolumn{2}{|c|}{ Main Effects } & \multirow{2}{*}{ 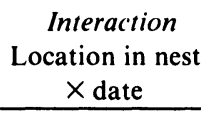 } \\
\hline & Location in nest & Date & \\
\hline \multicolumn{4}{|l|}{ Small nest } \\
\hline Sum of squares & 7 & 33 & 3 \\
\hline$F$ & 1.1 & $11.1^{* *}$ & 1.1 \\
\hline df & 2 & 1 & 1 \\
\hline$\%$ of variance explained & 8 & 39 & 4 \\
\hline \multicolumn{4}{|l|}{ Medium nest } \\
\hline Sum of squares & 21 & 333 & 180 \\
\hline$F$ & 0.4 & $4.8^{* *}$ & 1.0 \\
\hline df & 3 & 4 & 10 \\
\hline$\%$ of variance explained & 1 & 8 & 5 \\
\hline \multicolumn{4}{|l|}{ Large nest } \\
\hline Sum of squares & 57 & 278 & 105 \\
\hline$F$ & 1.4 & 5.0 & 0.8 \\
\hline df & 3 & 4 & 9 \\
\hline$\%$ of variance explained & 2 & 7 & 3 \\
\hline
\end{tabular}

$\mathrm{df}=$ degrees of freedom, ${ }^{*} \mathrm{p}<0.05,{ }^{* *} \mathrm{p}<0.01,{ }^{* * *} \mathrm{p}<0.001$

tages to flexibility in development time of larvae which allow more time for development when food is limiting, either because there are fewer females to harvest it, or because of a general scarcity of prey in the environment.

Data on development times were found in the literature for 4 populations of $P$. fuscatus, and 1 each of $P$. hunteri, $P$. annularis, $P$. gallicus and P. exclamans (Table 6). Development times varied from 10 to 25 days for eggs, from 15 to 25 days for larvae and from 13 to 22 days for pupae (Table 6). P. exclamans in this study falls towards the faster end of this range, particularly for pupa development time. All reports of pupa development times averaged over 18 days except Rabb's study of $P$. exclamans in N. Carolina. P. exclamans was studied in the most southern climate, so it is possible that the differences are due to temperature. There is a trend in P. fuscatus towards shorter pupa development times in more southern populations. $P$. exclamans and $P$. annularis are the only two members of the subgenus Aphanilopterus represented here. It is possible that Aphanilopterus, which generally has larger nest sizes and more adults tending 
TABLE 5. Correlations between development time, date and number of females on the nest.

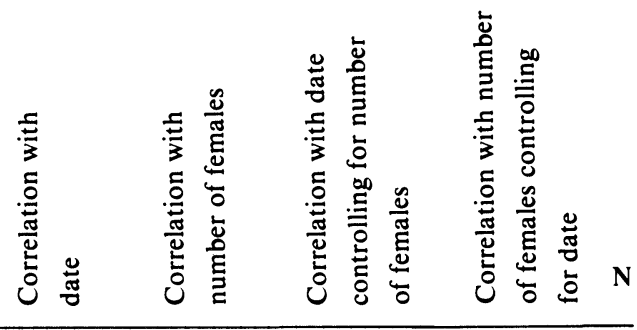

Egg development time

$\begin{array}{rcclcr}\text { Small nest } & -0.31^{*} & & & & 43 \\ \text { Medium nest } & -0.07 & -0.15^{* *} & 0.13^{* *} & -0.18^{* * *} & 340 \\ \text { Large nest } & 0.10^{*} & 0.10^{*} & 0.01 & 0.04 & 501\end{array}$

Larva development time

Small nest

Medium nest

$$
\begin{array}{rlllr}
-0.58^{* *} & & & & 28 \\
0.46^{* * *} & 0.40^{* * *} & 0.25^{* * *} & -0.04 & 296 \\
0.65^{* * *} & 0.30^{* * *} & 0.96^{* * *} & -0.93^{* * *} & 317
\end{array}
$$

Large nest

Pupa development time

\begin{tabular}{rllllr} 
Small nest & $-0.59^{* *}$ & & & & 19 \\
Medium nest & $-0.15^{*}$ & -0.11 & $-0.11^{*}$ & 0.05 & 218 \\
Large nest & -0.04 & $-0.16^{* *}$ & $0.25^{* *}$ & $0.29^{* * *}$ & 268 \\
& & & & & \\
\hline
\end{tabular}

${ }^{*} \mathrm{p}<0.05 ;{ }^{* *} \mathrm{p}<0.01 ;{ }^{* * *} \mathrm{p}<0.001$

the nest, also has faster development times (Strassmann, unpub.). This is not contradicted by the very long development times reported by Jeanne for $P$. annularis since these were early spring data, and are therefore not strictly comparable. Another factor that may result in selection for fast pupa development times is that nests of $P$. exclamans are very vulnerable to predation, and to loss of the nest due to death of all workers (Strassmann, 1981). Short pupa development times may reduce the probability of nest loss. But this 


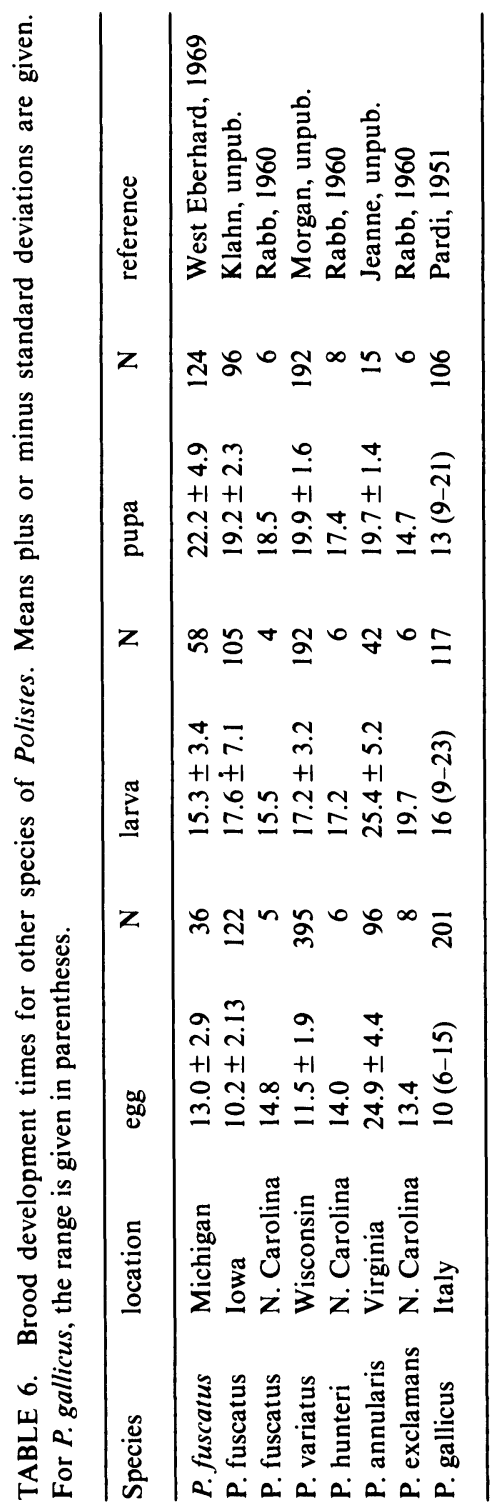


may also be the case for the other species of Polistes where data on nest failure rates are not available.

Polistes has slightly longer development times than other social wasps. Paravespula vulgaris, Dolichovespula sylvestris and Vespa crabro all have summer egg development times of about 5 days, larva development times of 10 to 15 days and pupa development times of 11 to 15 days (Spradbery, 1973). The shorter development times in these species as compared to Polistes may be due to the much larger colony sizes found in these species, as well as their ability to eat a greater variety of arthropods and carrion.

\section{ACKNOWLEDGEMENTS}

We thank Christi Steinbarger and Dana Meyer for help with field work, and Bill Mueller and Colin Hughes for their comments on the manuscript. This research was supported by NSF Postdoctoral Fellowship \#SPI-7914902 and NSF \#DEB80-05739 to JES.

\section{References Cited}

Haggard, C. M. and G. J. Gamboa

1980. Seasonal variation in body size and reproductive condition of a paper wasp, Polistes metricus (Hymenoptera: Vespidae). Canadian Entomologist 112:239-248.

JEANNE, R. L.

1975. The adaptiveness of social wasp nest architecture. Quarterly Review of Biology 50:267-287.

1979. A latitudinal gradient in rates of ant predation. Ecology 60:1211-1224.

PARDI, L.

1951. Studio dell attivita e della divisione di lavoro in una societa di Polistes gallicus (L.) dopo la comparsa delle operaie. (Ricerche sui Polistini XII). Archivio zoologico italiano 36:361-431.

RABB, R. L.

1960. Biological studies of Polistes in North Carolina (Hymenoptera: Vespidae). Annals of the Entomological Society of America 53:111-121.

SPRADbery, J. P.

1973. Wasps: an account of the biology and natural history of social and solitary wasps. University of Washington Press, Seattle, Washington, $408 \mathrm{pp}$.

Strassmann, J. E.

1981. Parasitoids, predators, and group size in the paper wasp, Polistes exclamans. Ecology 62:1225-1233.

West Eberhard, M. J.

1969. Social biology of polistine wasps. University of Michigan, Museum of Zoology, Miscellaneous Publications No. 140: 1-101. 

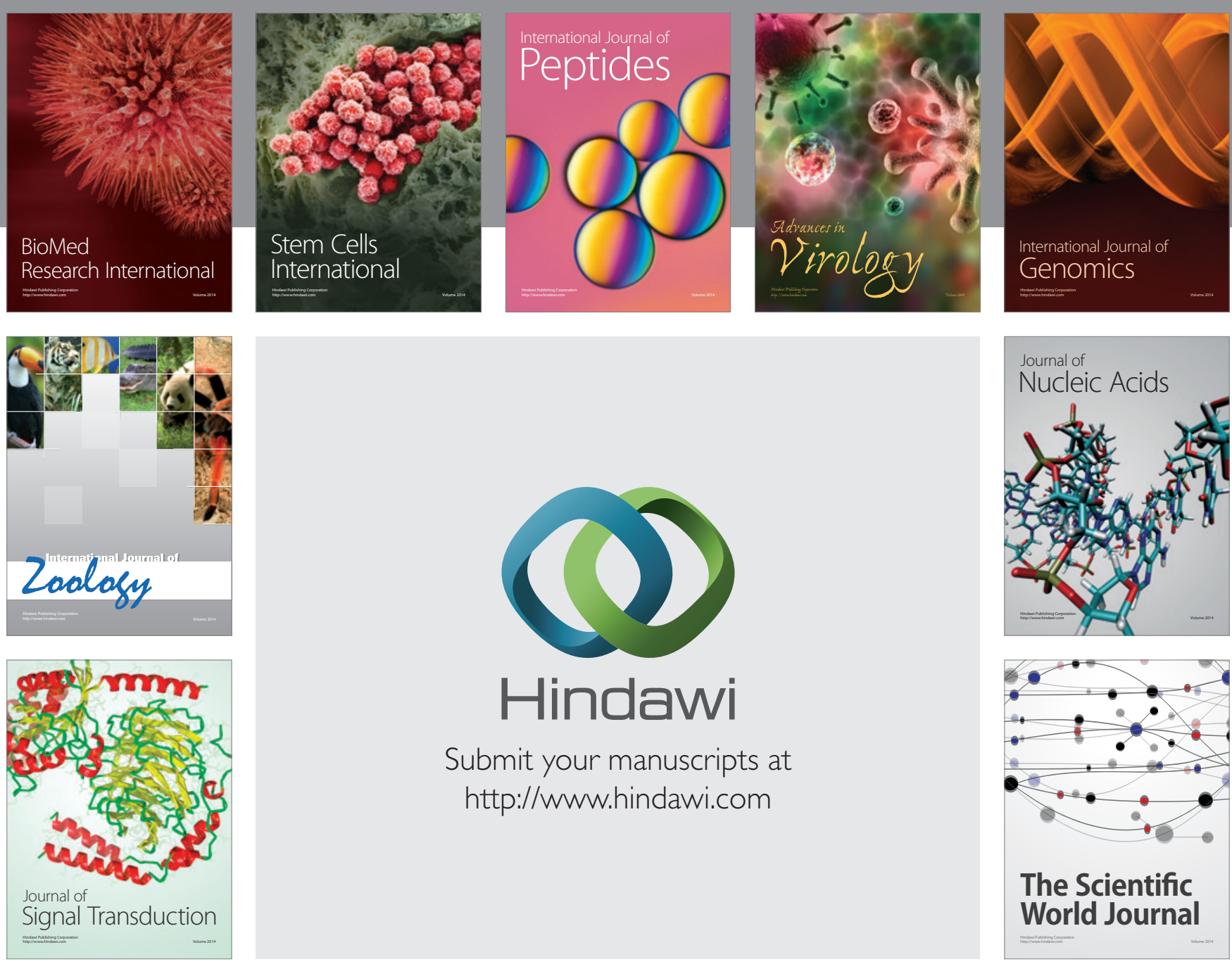

Submit your manuscripts at

http://www.hindawi.com
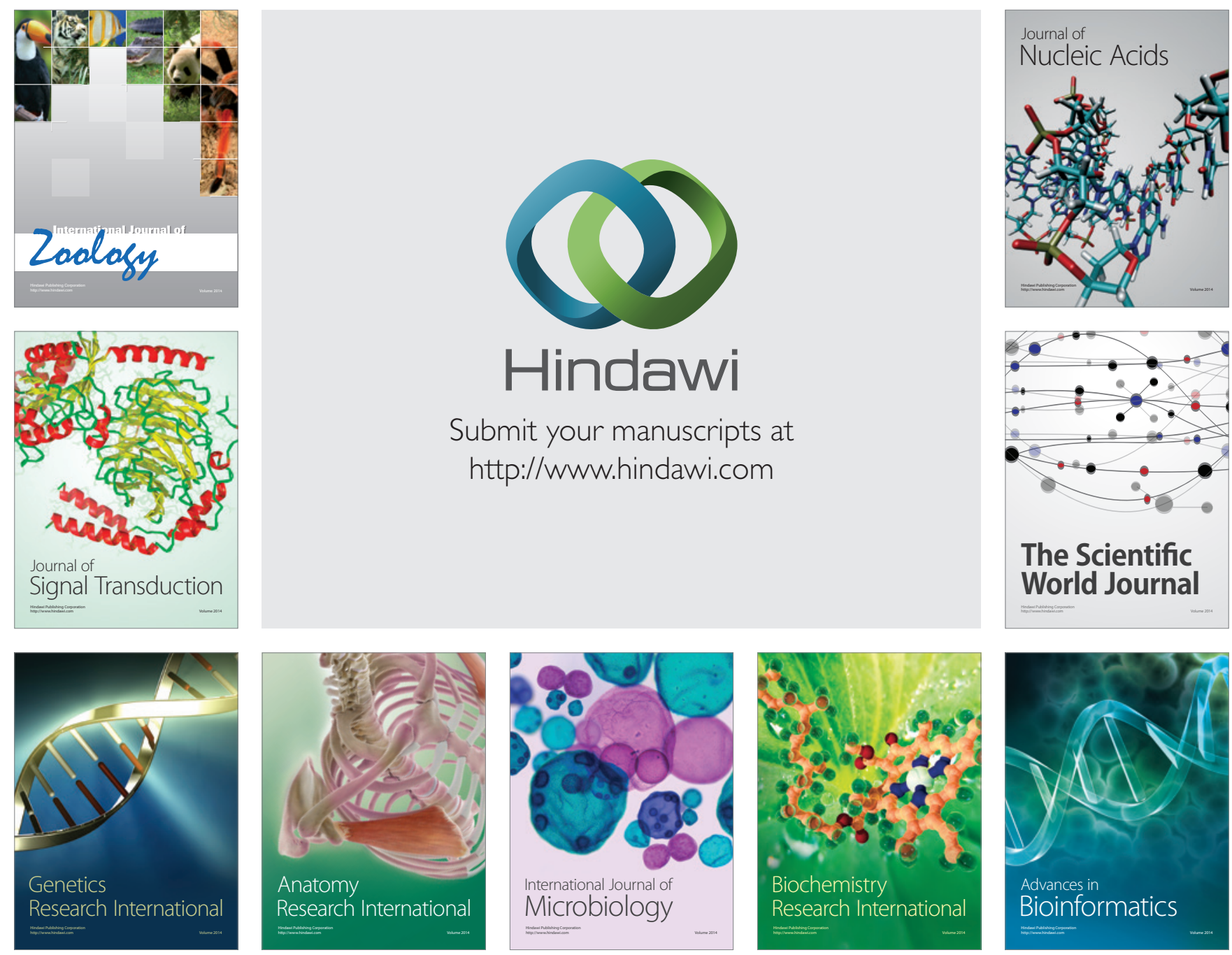

The Scientific World Journal
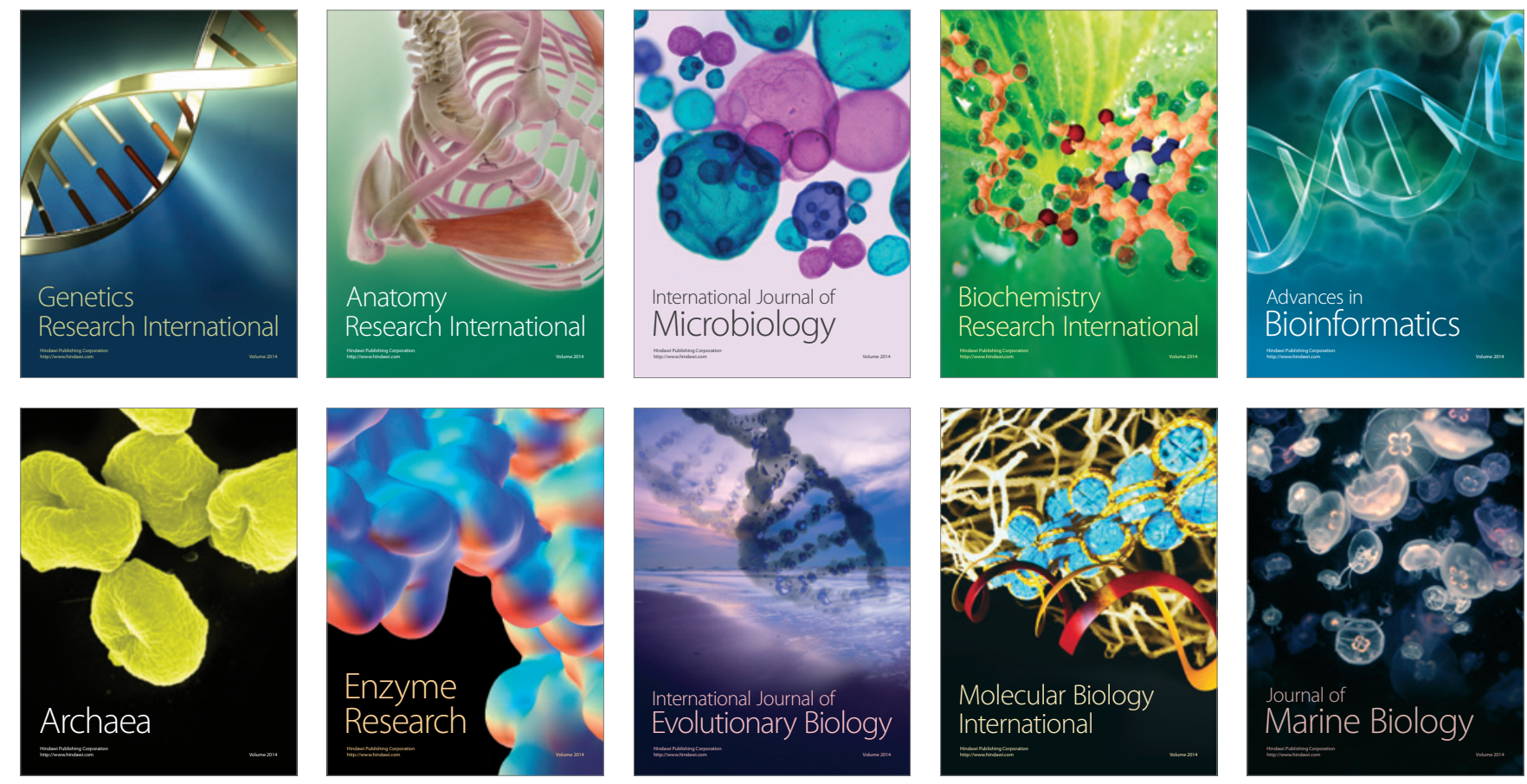